\title{
ANALISIS PENGARUH FRICTION DAMPER TERHADAP UPAYA RETROFITTING BANGUNAN DI JAKARTA
}

\author{
Giovanni Pranata \\ Jurusan Teknik Sipil, Universitas Tarumanagara Jakarta \\ giovannipranata@gmail.com
}

\begin{abstract}
ABSTRAK
Beberapa tahun terakhir ini sering terjadi gempa bumi khususnya di Indonesia karena letaknya yang berada di pertemuan antar lempeng bumi. Tidak sedikit korban yang timbul akibat bencana ini.. Oleh karena itu saat ini perlu ditinjau mengenai kelayakan bangunan-bangunan lama untuk menahan gaya gempa khususnya gaya gempa yang sesuai dengan peraturan SNI gempa yang baru. Makalah ini membahas salah satu usaha dalam memperbaiki ketahanan suatu bangunan terhadap gaya gempa, yaitu dengan menggunakan alat peredam (damper) khususnya friction damper. Untuk mengetahui besarnya pengaruh alat peredam dalam suatu bangunan, maka dilakukan analisis bangunan terhadap gaya gempa untuk mendapatkan beberapa parameter komparatif untuk membandingkan tingkah laku antara bangunan tanpa peredam dan menggunakan alat peredam. Analisis dalam hal ini dibantu dengan menggunakan program SAP 2000. Hasilnya menunjukan bahwa alat peredam memberikan peningkatan performa bangunan yang cukup baik untuk menahan gaya gempa sehingga pemasangan damper pada bagunan lama menjadi salah satu solusi yang baik.
\end{abstract}

Kata kunci: gempa, perbaikan, redaman, friction damper

\section{PENDAHULUAN}

Bangunan khususnya bangunan tinggi perlu memperhatikan bahaya dari getaran yang terjadi karena dapat menimbulkan kerusakan atau bahkan keruntuhan pada bangunan, salah satu penyebab getaran adalah gempa bumi. Gempa merupakan fenomena alam yang paling mengkhawatirkan, karena tempat dan waktu yang tidak dapat diperkirakan kapan akan terjadinya. Indonesia merupakan negara yang berada di pertemuan lempeng bumi sehingga rawan terjadi gempa dan oleh karena itu di Indonesia telah dilakukan pembaharuan peraturan gempa sebanyak tiga kali yaitu peraturan muatan Indonesia tahun 1970, peraturan gempa untuk gedung pada tahun 1983, SNI gempa 2002, dan SNI gempa 2012.

Di Indonesia, sebagian besar bangunan yang dibangun sebelum tahun 2002 (desain struktur memakai peraturan gempa tahun 1983 dan sebelumnya) umumnya mempunyai daktilitas yang kurang memadai. Dari beberapa penelitian didapati bahwa bangunan beton bertulang yang tidak daktail sebagian besar akan mengalami kerusakan dan bahkan runtuh bila terkena gempa kuat, oleh karena itu perlu dilakukan penelitian untuk memperbaiki dan memperkuat bangunanbangunan lama terhadap peraturan gempa yang baru.

Saat ini berbagai cara telah diteliti untuk mengurangi efek yang ditimbulkan gempa berkaitan dengan bagaimana dan seberapa besar energi didistribusikan ke dalam bangunan pada saat gempa bumi terjadi. Energi ini masuk ke dalam struktur dalam bentuk energi kinetik dan energi potensial kemudian diserap dan dilepaskan sebagian. Seperti diketahui, getaran struktur akan mendekati tak terhingga apabila tanpa redaman, tetapi redaman pada struktur selalu ada bergantung pada properti bangunan itu. Selain itu peningkatan efisiensi dari struktur dapat dilakukan dengan menambahkan peredam (Zahrai, S.M, et al., 2014).

Menambahkan redaman dan kekakuan elemen berdasarkan deformasi plastis pada baja ringan untuk mendisipasi energi sehingga mengurangi respon juga dikemukakan oleh Scholl, 1996. Redaman adalah suatu proses dimana sistem struktur mendisipasi dan menyerap energi yang masuk ke dalam bangunan dari eksitasi eksternal. Karena itu peredam (damper) mengurangi penambahan energi regangan dan respon dari sistem, terutama kondisi dimana mendekati resonansi dimana peredam mengontrol respon. Besarnya nilai redaman tergantung dari beberapa 
faktor seperti amplitudo getaran, material konstruksi, periode getaran, mode shapes, dan konfigurasi struktur.

Ada beberapa jenis perangkat kontrol pasif dan peredam. Friction dampers pasif menggunakan gesekan Coulomb untuk mendisipasi energi yang masuk akibat gempa. Alat redaman ini telah digunakan secara luas dalam berbagai proyek perkuatan di seluruh dunia, karena biayanya yang rendah dan kinerja yang baik. Selain itu, Passive dampers adalah bentuk yang paling lama dan umum digunakan. Passive dampers biasanya ditempatkan pada cross bracing diantara dua lantai yang berdekatan. Passive dampers menggunakan perpindahan dari lantai untuk menghasilkan gaya readaman pada bangunan. Tidak seperti perangkat aktif dan semi-aktif, perangkat pasif tidak dapat merubah sifat redamannya berdasarkan respon dari struktur dan karena itu tidak memerlukan sumber energi listrik atau kontrol algoritma untuk beroperasi. Tanpa peralatan sensor atau komputasi, perangkat pasif umumnya yang paling ekonomis dan paling banyak digunakan.

Sejak awal tahun 1970 berbagai jenis perangkat disipasi telah diuji dan digunakan. Perangkat ini dapat dikelompokkan menjadi tiga kategori : peredam viskos dan viskoelastik (viscous and viscoelastic dampers), peredam metalik (metalic dampers), dan peredam gesekan (friction dampers).

Dalam penelitian ini digunakan friction damper sebagai elemen peredamnya, Alat ini bergantung pada tahanan yang diberikan oleh gesekan antara kedua permukaan material. Selama gempa terjadi, alat akan mulai slip pada batas gaya tertentu, apabila gaya tersebut belum tercapai maka redaman pada alat ini belum bekerja melainkan pengaruh yang diberikan hanya kekakuan oleh bracing yang ada. Salah satu alat friction dampers adalah slotted bolted connection (SBC).

Friction damper umumnya dipasang pada bracing bangunan. Dengan menggunakan bracing maka defleksi bangunan berkurang seiring dengan meningkatnya kekakuan tetapi sebaliknya gaya geser dasar menjadi lebih besar karena kekakuan bangunan yang meningkat, oleh karena itu friction damper dipasang pada bracing untuk membantu mengurangi gaya geser dasar dengan disipasi energi (Kaur, Navel, et al., 2012).

Untuk mendisipasi energi, friction damper harus dibebani di atas ambang batas slip, dengan demikian alat redaman ini tidak bekerja untuk getaran yang kecil. Alat redaman tersebut pada dasarnya non-linear dan bekerja efektf pada gempa yang besar.

Pengaruh damper terhadap gaya gempa suatu bangunan dapat dilihat dari persamaan energi. proses respon struktur terhadap gaya gempa dapat diilustrasikan menggunakan konsep energi, persamaan energi adalah:

$\mathrm{E}_{\mathrm{i}}=\mathrm{E}_{\mathrm{k}}+\mathrm{E}_{\mathrm{s}}+\mathrm{E}_{\mathrm{h}}+\mathrm{E}_{\mathrm{d}}$

dimana $E_{i}$ adalah energi gempa yang masuk, $E_{k}$ adalah energi kinetik, $E_{s}$ adalah energi regangan elastik, $\mathrm{E}_{\mathrm{h}}$ adalah energi hysteretic, dan $\mathrm{E}_{\mathrm{d}}$ adalah energi yang didisipasi oleh redaman struktur.

Sisi sebelah kanan persamaan adalah kapasitas energi dari struktur dan sebelah kiri adalah energi yang dikeluarkan oleh gempa terhadap struktur. Agar struktur dapat menahan gaya gempa maka kapasitas energi dari srtuktur harus lebih besar daripada yang dikeluarkan oleh gempa. Pada desain gempa konvensional, kapasitas energi struktur sebagian besar bergantung dari energi hysteretic, $\mathrm{E}_{\mathrm{h}}$, dimana energi yang dihasilkan dari deformasi inelastik dari srtuktur. Dengan kata lain struktur utama akan terlindungi dan respon struktur terhadap gaya gempa dapat ditingkatkan.

Dari sekian banyak bentuk gesekan yang dapat mengurangi getaran dan kerusakan pada struktur, tipe yang paling populer adalah solid friction. Oleh karena itu sebagian besar penelitian menggunakan teori solid friction sebagai dasarnya, hal itu juga bergantung kepada beberapa 
hipotesis seperti konsep gesek Coulomb. Sesaat sebelum terjadi gesekan dan ketika gesekan terjadi, gaya gesekan , F, dapat digambarkan sebagai:

$\mathrm{F}=\mu \mathrm{N}$

dimana $\mathrm{N}$ adalah gaya normal yang bekerja, dan $\mu$ adalah koefisien gesekan. Umumnya koefisien gesekan lebih besar pada waktu sebelum terjadi gesekan, maka koefisien gesekan dibagi menjadi dua yaitu statik $\left(\mu_{\mathrm{s}}\right)$ dan kinetik $\left(\mu_{\mathrm{k}}\right)$.

Dalam struktur dengan friction damper (FDBF), periode struktur dipengaruhi oleh slip load dan jenis tingkat gerakan gempa. Oleh karena itu, menjadi sangat sulit untuk terjadinya resonansi pada struktur. Dengan menyeleksi besarnya slip load sangat memungkinkan bagi kita untuk mengatur agar respons struktur mencapai nilai optimum.

Total energi yang dipancarkan oleh gesekan adalah sama dengan hasil dari penyimpangan atau penahan beban (product of slip load) dan jarak penyimpangannya pada masing-masing damper. Saat penyimpangan beban sangat tinggi, energi yang dipancarkan akan rendah karena tidak ada penyimpangan. Pada kondisi ini struktur berprilaku sebagai braced frame. Saat slip load diatur untuk gaya yang sangat rendah, penyimpangan besar terjadi dan menyebabkan jumlah energi yang dipancarkan hampir tidak ada. Pada kondisi ini struktur berprilaku sebagai unbraced frame. Di antara kedua titik ekstrim inilah terdapat nilai antara yang akan memberikan pemancaran energi maksimum. Nilai inilah yang kemudian disebut sebagai penyimpangan beban optimum atau optimum slip load. Dan rentang nilai penyimpangan beban yang menghasilkan pemancaran energi optimum yang disebut distribusi beban simpang optimum.

Hubungan antara besarnya nilai slip load dan respons struktur dapat dilihat pada Gambar 1. Dari gambar dapat dilihat bahwa optimum slip load akan memberikan respons struktur yang optimum.

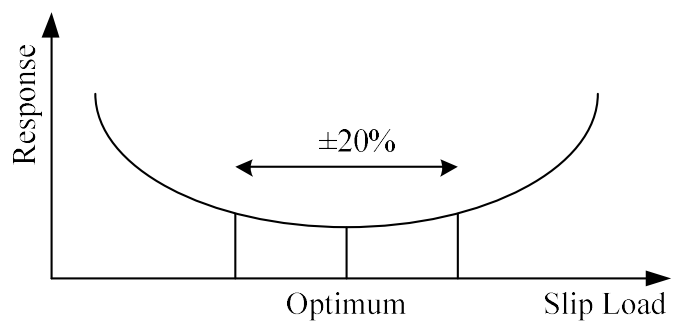

Gambar 1. Kurva respons struktur terhadap slip load

Kriteria ini dipakai untuk memperoleh perkiraan nilai slip load. Pengoptimalan dari nilai slip load membutuhkan tahapan dari non-linear time history analysis, di mana slip load divariasikan dan amplitudo respons dievaluasi. Penelitian oleh Filiatrault dan Cherry, 1987 mendapatkan bahwa nilai kisaran $25 \%$ dari optimum slip load tidak akan mempengaruhi respons struktur secara signifikan. Oleh karena itu, kisaran $8 \%-10 \%$ dari optimum slip load dapat dipakai tanpa harus melakukan penyesuaian pada friction damper .

Secara umum, batas bawah dari slip load diperkirakan 130\% dari beban angin, sedangkan batas atas sekitar $75 \%$ dari beban yang menyebabkan struktur mengalami runtuh. Seleksi dari nilai slip load harus dapat memastikan bahwa setelah gempa terjadi, sistem struktur akan dapat kembali seperti bentuk semula karena masih dalam batas elastisitas struktur.

\section{METODE PENELITIAN}

Studi ini menganalisis suatu gedung yang didirikan dengan menggunakan peraturan gempa lama. Analisis dengan bantuan program SAP dilakukan dengan kondisi yang berbeda-beda yaitu 
dengan dan tanpa menggunakan damper, kemudian gaya-gaya yang terjadi di bandingkan dan pada akhirnya dilakukan pengecekan kekuatan terhadap elemen-elemen struktur eksisting.

\section{Data bangunan}

Bangunan yang akan ditinjau untuk analisis adalah bangunan lama yang berada di Jakarta, bangunan ini merupakan gedung perkantoran 10 lantai. Struktur bangunan ini menggunakan sistem portal terbuka dan ketinggian mencapai $39.7 \mathrm{~m}$, denah lantai gedung ini seragam untuk setiap lantai seperti dapat dilihat pada Gambar 2.

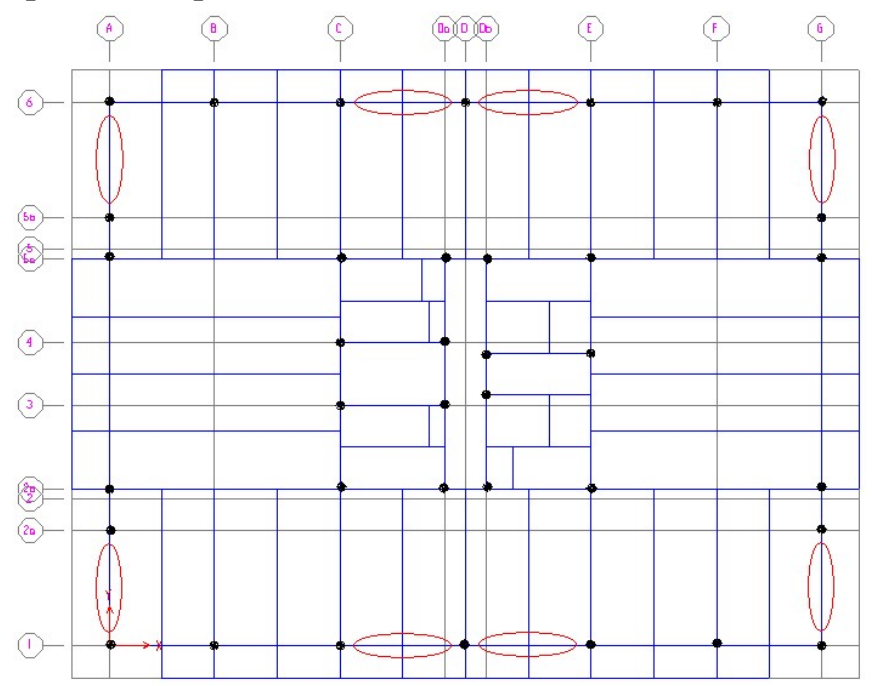

Gambar 2. Denah Gedung

Gedung ini selesai didirikan pada tahun 1985 dengan dasar perencanaan menggunakan peraturan gempa tahun 1983, dan sampai saat ini gedung masih aktif digunakan sesuai dengan fungsi awal gedung yaitu sebagai bangunan perkantoran.

\section{Beban gempa}

Dalam pembahasan dilakukan analisis dengan non-linear. Rekaman gempa yang di pakai adalah time history untuk gempa berdasarkan peraturan SNI 2002 wilayah 3 tanah sedang, seperti dapat dilihat pada Gambar 3. Waktu gempa yang dipakai dalam analisis adalah 10 detik.

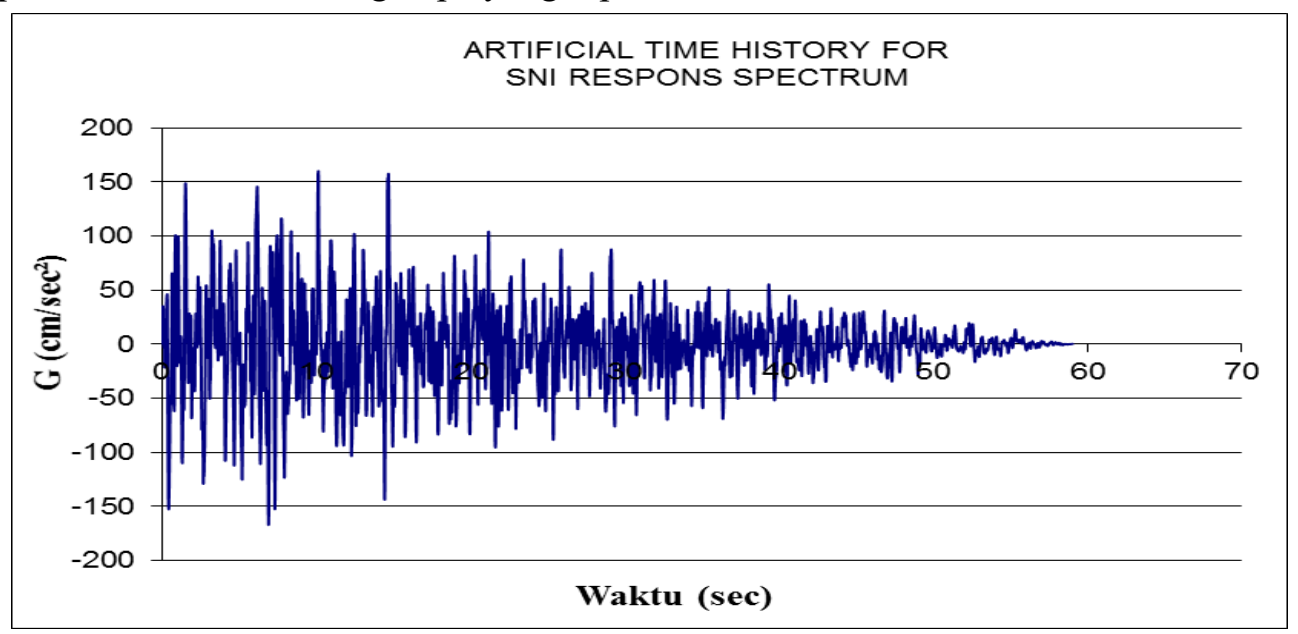

Gambar 3. Time history SNI 2002 Wilayah 3 Tanah Sedang 


\section{Koefisien dan letak damper}

Dalam permodelan friction damper perlu dihitung terlebih dulu nilai slip load dari damper yang dibutuhkan. Prosedur nilai optimum slip load pada struktur dengan friction damper (FDBF) tersebut dimuat dalam jurnal ASCE Vol. 116 no. 5 berjudul "Seismic Design Spectra for Friction-Damped Structures". Perletakan friction damper dapat dilihat pada Gambar 4.
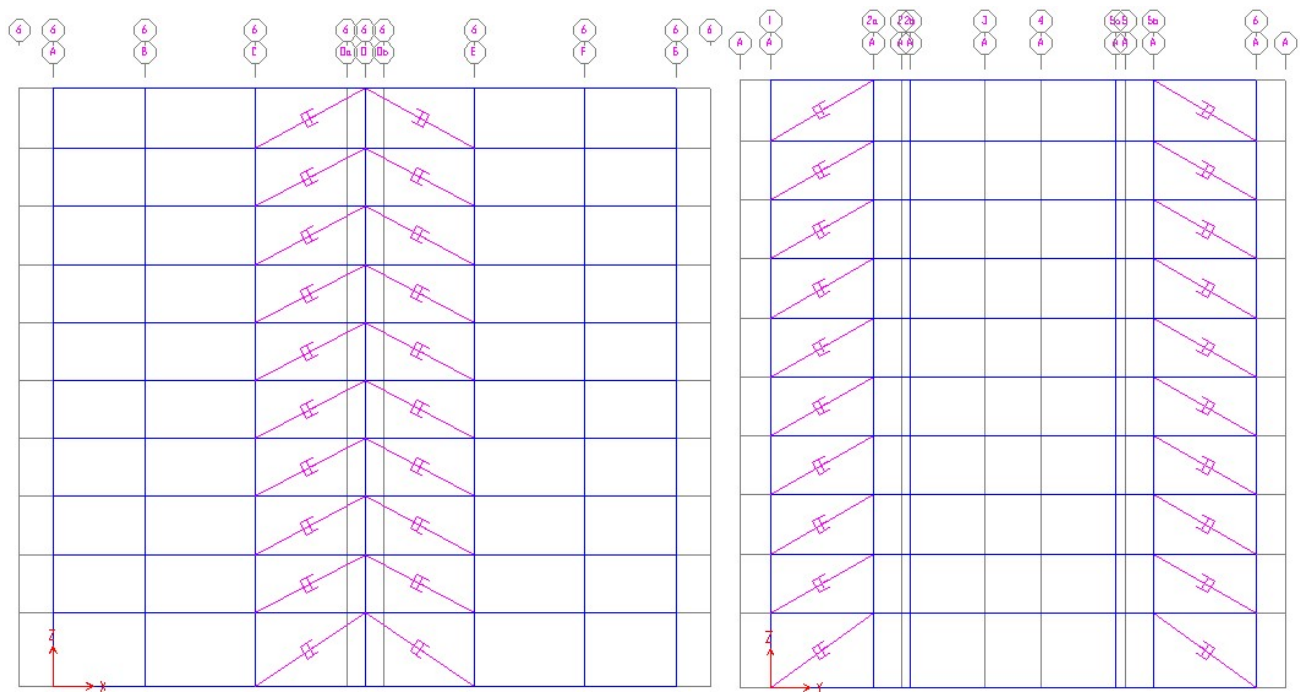

Gambar 4. Portal As 1,6,A, dan G.

Analisis free vibration dan respon spektra diselesaikan dengan menggunakan bantuan program elemen hinga SAP 2000. Periode getar alami dan mode shape struktur didapat dari analisis free vibration. Dari respon spektra analisis didapat gaya geser dasar, deformasi, dan gaya-gaya dalam (gaya geser, momen, dan aksial).

\section{HASIL ANALISIS}

Karena damper yang digunakan adalah friction damper, maka periode getar untuk bangunan dengan damper lebih kaku karena friction damper menyumbang kekakuan pada struktur keseluruhan. Periode getar untuk keduanya dapat dilihat pada Tabel 1.

Tabel 1. Mode shape berdasarkan periode getar

\begin{tabular}{ccc}
\hline \multirow{2}{*}{ Mode } & \multicolumn{2}{c}{ Periode getar $(\mathrm{sec})$} \\
\cline { 2 - 3 } & Struktur tanpa damper & Struktur dengan damper \\
\hline 1 & 2.464447 & 1.764358 \\
\hline 2 & 2.408417 & 1.190065 \\
\hline 3 & 2.138661 & 0.96609 \\
\hline 4 & 0.824032 & 0.574495 \\
\hline 5 & 0.798853 & 0.408747 \\
\hline 6 & 0.716569 & 0.383665 \\
\hline 7 & 0.449641 & 0.378741 \\
\hline
\end{tabular}

Deformasi struktur berubah dengan adanya penambahan damper (garis biru). Selain itu terlihat bahwa terjadi reduksi deformasi sekitar $60 \%$ untuk arah $\mathrm{X}$ dan $\mathrm{Y}$ akibat penambahan damper 
dari hasil analisis respon spektra. Kemudian diketahui juga bahwa terjadi peningkatan deformasi hampir linear seiring dengan meningkatnya tinggi struktur. Data lengkap deformasi struktur dapat dilihat pada Tabel 2.

Tabel 2. Tabel deformasi srtuktur

\begin{tabular}{|c|c|c|c|c|c|c|}
\hline \multirow{3}{*}{ Story } & \multicolumn{2}{|c|}{ Damped } & \multicolumn{2}{|c|}{ Un-Damped } & \multirow{3}{*}{$\frac{\%}{\mathrm{X}}$} & \multirow{3}{*}{$\begin{array}{l}\% \\
\mathrm{Y}\end{array}$} \\
\hline & \multicolumn{2}{|c|}{ Displacement $(\mathrm{cm})$} & \multicolumn{2}{|c|}{ Displacement $(\mathrm{cm})$} & & \\
\hline & $X$ & $\mathrm{Y}$ & $\mathrm{X}$ & $\mathrm{Y}$ & & \\
\hline 1 & 2.531019 & 1.568145 & 3.386326 & 3.682377 & 25.258 & 57.415 \\
\hline 2 & 3.30304 & 2.767722 & 6.209842 & 6.589254 & 46.810 & 57.996 \\
\hline 3 & 3.925555 & 3.840924 & 9.016499 & 9.360841 & 56.463 & 58.968 \\
\hline 4 & 4.665911 & 4.718723 & 11.69976 & 11.8987 & 60.120 & 60.343 \\
\hline 5 & 5.390442 & 5.366029 & 14.19417 & 14.30707 & 62.024 & 62.494 \\
\hline 6 & 6.173823 & 5.931288 & 16.39602 & 16.5404 & 62.346 & 64.141 \\
\hline 7 & 6.945176 & 6.411949 & 18.30597 & 18.49542 & 62.061 & 65.332 \\
\hline 8 & 7.671973 & 6.764573 & 19.92883 & 20.04338 & 61.503 & 66.250 \\
\hline 9 & 8.346158 & 7.3593 & 21.36853 & 21.13892 & 60.942 & 65.186 \\
\hline 10 & 8.923468 & 7.906852 & 22.38764 & 21.93069 & 60.141 & 63.946 \\
\hline
\end{tabular}

Reduksi gaya aksial maksimum terdapat pada lantai 10 yaitu sebesar 20\%. Reduksi ini disebabkan karena adanya friction damper, maka terbukti bahwa sebagian besar gaya gempa telah diserap oleh damper. Data lengkap gaya aksial kolom dapat dilihat pada Tabel 3.

Tabel 3. Tabel gaya aksial kolom

\begin{tabular}{|c|c|c|c|c|c|c|}
\hline \multirow{3}{*}{ Story } & \multicolumn{2}{|c|}{ Damped } & \multicolumn{2}{|c|}{ Un-Damped } & \multirow{3}{*}{$\begin{array}{l}\% \\
\mathrm{X}\end{array}$} & \multirow{3}{*}{$\begin{array}{l}\% \\
\mathrm{Y}\end{array}$} \\
\hline & \multicolumn{2}{|c|}{ Aksial C (Ton) } & \multicolumn{2}{|c|}{ Aksial C (Ton) } & & \\
\hline & $\mathrm{X}$ & $\mathrm{Y}$ & $\mathrm{X}$ & $\mathrm{Y}$ & & \\
\hline 1 & 45.3774 & 45.3774 & 181.6366 & 181.6366 & 75.01748 & 75.01748 \\
\hline 2 & 35.058 & 35.058 & 153.7265 & 153.7265 & 77.19456 & 77.19456 \\
\hline 3 & 30.7717 & 30.7717 & 127.6416 & 127.6416 & 75.89211 & 75.89211 \\
\hline 4 & 25.616 & 25.616 & 102.9213 & 102.9213 & 75.11108 & 75.11108 \\
\hline 5 & 20.5064 & 20.5064 & 79.8019 & 79.8019 & 74.30337 & 74.30337 \\
\hline 6 & 15.7873 & 15.7873 & 58.922 & 58.922 & 73.20644 & 73.20644 \\
\hline 7 & 11.5756 & 11.5756 & 40.1267 & 40.1267 & 71.15237 & 71.15237 \\
\hline 8 & 8.2598 & 8.2598 & 25.0014 & 25.0014 & 66.96265 & 66.96265 \\
\hline 9 & 5.2006 & 5.2006 & 12.6573 & 12.6573 & 58.91225 & 58.91225 \\
\hline 10 & 2.4812 & 2.4812 & 4.0822 & 4.0822 & 39.21905 & 39.21905 \\
\hline
\end{tabular}


Dengan penambahan damper pada struktur maka momen yang terjadi pada kolom menjadi lebih kecil. Presentase reduksi gaya momen dapat dilihat pada Tabel 4.

Tabel 4. Tabel gaya momen kolom

\begin{tabular}{|c|c|c|c|c|c|c|}
\hline \multirow{3}{*}{ Story } & \multicolumn{2}{|c|}{ Damped } & \multicolumn{2}{|c|}{ Un-Damped } & \multirow{3}{*}{$\begin{array}{l}\% \\
\mathrm{X}\end{array}$} & \multirow{3}{*}{$\begin{array}{l}\% \\
\mathrm{Y}\end{array}$} \\
\hline & \multicolumn{2}{|c|}{ Momen C (Ton-m) } & \multicolumn{2}{|c|}{ Momen C (Ton-m) } & & \\
\hline & $X$ & $\mathrm{Y}$ & $\mathrm{X}$ & $\mathrm{Y}$ & & \\
\hline 1 & 61.59288 & 36.28518 & 73.45972 & 85.19889 & 16.15421 & 57.41121 \\
\hline 2 & 22.22504 & 6.75116 & 36.82112 & 22.39437 & 39.64051 & 69.85332 \\
\hline 3 & 12.38071 & 8.23727 & 33.64563 & 27.94112 & 63.20262 & 70.51918 \\
\hline 4 & 10.7301 & 6.70984 & 33.80298 & 27.28526 & 68.25694 & 75.40855 \\
\hline 5 & 9.132 & 6.98633 & 27.1427 & 23.13821 & 66.35559 & 69.80609 \\
\hline 6 & 10.47036 & 7.74487 & 28.14696 & 23.25246 & 62.8011 & 66.69226 \\
\hline 7 & 8.35438 & 6.58978 & 21.54188 & 17.74534 & 61.21796 & 62.86473 \\
\hline 8 & 8.90929 & 5.9055 & 19.03223 & 15.37589 & 53.18841 & 61.59247 \\
\hline 9 & 8.21104 & 3.94161 & 11.91892 & 10.01831 & 31.10919 & 60.65594 \\
\hline 10 & 9.34949 & 1.18771 & 8.41466 & 5.9908 & -11.1095 & 80.17443 \\
\hline
\end{tabular}

Terlihat reduksi yang cukup besar terjadi pada gaya geser balok. Reduksi ini juga akibat dari pemasangan damper pada struktur. Reduksi rata-rata untuk arah $\mathrm{X}$ lebih besar daripada arah $\mathrm{Y}$ karena nilai koefisien redaman arah X lebih besar dari pada arah Y. Data lengkap gaya geser balok dapat dilihat pada Tabel 5 .

Tabel 5. Tabel gaya geser balok

\begin{tabular}{|c|c|c|c|c|c|c|}
\hline \multirow{3}{*}{ Story } & \multicolumn{2}{|c|}{ Damped } & \multicolumn{2}{|c|}{ Un-Damped } & \multirow[b]{2}{*}{$\%$} & \multirow[b]{2}{*}{$\%$} \\
\hline & \multicolumn{2}{|c|}{ Geser B (Ton) } & \multicolumn{2}{|c|}{ Geser B (Ton) } & & \\
\hline & $\mathrm{X}$ & $\mathrm{Y}$ & $\mathrm{X}$ & $\mathrm{Y}$ & $\mathrm{X}$ & $\mathrm{Y}$ \\
\hline 1 & 18.7351 & 10.3744 & 37.0482 & 27.1101 & 49.43047 & 61.73234 \\
\hline 2 & 7.9132 & 8.1096 & 34.4826 & 23.9146 & 77.05161 & 66.08933 \\
\hline 3 & 9.3676 & 6.264 & 31.7923 & 22.1437 & 70.535 & 71.71204 \\
\hline 4 & 9.2707 & 4.6244 & 28.5002 & 20.267 & 67.47146 & 77.18261 \\
\hline 5 & 8.8212 & 3.89 & 25.6109 & 18.6173 & 65.55685 & 79.10546 \\
\hline 6 & 8.6852 & 4.3027 & 23.1749 & 16.9648 & 62.52325 & 74.63748 \\
\hline 7 & 7.976 & 4.0775 & 19.3036 & 13.8694 & 58.68128 & 70.60075 \\
\hline 8 & 7.9131 & 3.457 & 15.5639 & 11.0537 & 49.15734 & 68.7254 \\
\hline 9 & 8.1672 & 2.033 & 10.6799 & 7.425 & 23.52737 & 72.61953 \\
\hline 10 & 4.3 & 0.8575 & 4.9606 & 3.8111 & 13.31694 & 77.49993 \\
\hline
\end{tabular}


Pada dasarnya, reduksi momen pada balok disebabkan juga karena reduksi gaya geser pada balok tersebut sehingga bila kita perhatikan maka besar reduksi momen balok dan geser balok hampir sama. Data lengkap gaya geser balok dapat dilihat pada Tabel 6.

Tabel 6. Tabel gaya momen balok

\begin{tabular}{|c|c|c|c|c|c|c|}
\hline \multirow{3}{*}{ Story } & \multicolumn{2}{|c|}{ Damped } & \multicolumn{2}{|c|}{ Un-Damped } & \multirow{3}{*}{$\begin{array}{l}\% \\
X\end{array}$} & \multirow{3}{*}{$\begin{array}{l}\% \\
\mathrm{Y}\end{array}$} \\
\hline & \multicolumn{2}{|c|}{ Momen B (Ton) } & \multicolumn{2}{|c|}{ Momen B (Ton) } & & \\
\hline & $\mathrm{X}$ & $\mathrm{Y}$ & $\mathrm{X}$ & $\mathrm{Y}$ & & \\
\hline 1 & 39.88975 & 24.43735 & 79.86588 & 65.66283 & 50.05408 & 62.78359 \\
\hline 2 & 15.99197 & 18.50149 & 74.02224 & 57.5976 & 78.39572 & 67.87802 \\
\hline 3 & 18.89267 & 14.05865 & 68.88553 & 53.6459 & 72.57382 & 73.79362 \\
\hline 4 & 18.43313 & 9.69507 & 61.40985 & 48.90852 & 69.98343 & 80.17713 \\
\hline 5 & 17.37722 & 7.72034 & 55.60273 & 45.42008 & 68.74754 & 83.00236 \\
\hline 6 & 16.76372 & 8.40226 & 49.95838 & 41.22133 & 66.44463 & 79.61672 \\
\hline 7 & 15.11078 & 7.95956 & 41.73512 & 34.08632 & 63.79361 & 76.64881 \\
\hline 8 & 14.99082 & 6.24913 & 33.48779 & 26.98555 & 55.23497 & 76.84268 \\
\hline 9 & 15.70223 & 3.83679 & 22.73776 & 17.87951 & 30.94205 & 78.54085 \\
\hline 10 & 6.02032 & 3.02104 & 10.2907 & 9.09929 & 41.49747 & 66.79917 \\
\hline
\end{tabular}

\section{KESIMPULAN DAN SARAN}

Kesimpulan yang dapat diambil dari analisis ini adalah :

1. Berdasarkan analisis ini dapat ditunjukkan bahwa respon daripada struktur terhadap gempa dapat diturunkan dengan menggunakan perangkat damper.

2. Dari hasil yang ditunjukan dalam analisis ini membuktikan bahwa penggunaan damper dalam retrofitting suatu bangunan adalah merupakan salah satu cara yang cukup efektif.

3. Dengan menggunakan friction damper maka frekuensi alami suatu bangunan akan berubah menjadi lebih kecil.

4. Dapat dilihat dengan adanya pembaharuan pada peraturan gempa di Indonesia bahwa telah terjadi peningkatan besarnya gaya gempa dari peraturan gempa tahun 2002 dan 2013, terlebih lagi dari peraturan gempa tahun 83 dan 70. Oleh karena itu disarankan agar diadakan peninjauan ulang terhadap bangunan-bangunan khususnya bangunan tinggi di jakarta yang dibangun sebelum peraturan 2002 diberlakukan.

Berdasarkan kesimpulan serta pengalaman selama penyusunan makalah ini, penulis perlu menyampaikan beberapa saran, yaitu:

1. Dalam makalah ini hanya dibahas mengenai friction damper, sedangkan masih banyak jenis damper yang perlu dianalisis dan dibahas lebih lanjut. Oleh karena itu disarankan agar mengembangkan lebih lanjut studi mengenai damper ini dengan lebih mendalam dan luas.

2. Perlunya perhatian yang besar dari para ahli struktur di Indonesia terhadap pengembangan alat damper, mengingat wilayah Indonesia merupakan wilayah potensial gempa. Terlebih lagi dengan adanya peraturan gempa yang baru maka bukan tidak 
mungkin banyak bangunan tinggi yang sudah tidak memenuhi syarat-syarat ketahanan gempa sehingga perlu di adakan retrofitting.

\section{REFERENSI}

Cheng, Franklin Y., Hongping Jiang., Kangyu Lou (2008), Smart Structures Innovative Systems for Seismic Response Control, USA.

Filiatrault, A. \& Cherry, S. (1987), Performance Evaluation of Friction Damped Braced Steel Frames Under Simulated Earthquake Loads.

Kaur, Naveet., V. A. Matsagar., A. K. Nagpal (2012), Earthquake Response of Mid-rise to Highrise Buildings with Friction Dampers, India.

SNI-1726-2002 (2002), Tata Cara Perencanaan Ketahanan Gempa untuk Bangunan Gedung, Departemen Pekerjaan Umum.

Song, T.T \& G.F. Dargush (1997), Passive Energy Dissipation Systems in Structural Engineering, USA.

Zahrai, S.M., M. S. Bozorgvar., M. H. Bozorgvar (2014), Application of Friction Pendulum Damper in Braced Frames and Its Effects on Structural Response. 